\title{
PERANCANGAN MEDIA VIDEO ANIMASI PADA INSTALASI MESIN LISTRIK PADA SEKOLAH TINGGI TEKNOLOGI BONTANG
}

\author{
Akbar ${ }^{1}$ \\ ${ }^{1}$ Teknik Elektro, Sekolah Tinggi Teknologi Bontang \\ akbarliwang@gmail.com
}

\begin{abstract}
ABSTRAK
Aktivitas pembelajaran dimasa pandemi covid-19 dilaksanakan secara daring/online. Penggunaan media dua dimensi dinilai tidak cukup bersinergi dengan media realita khususnya mesin-mesin listrik yang memiliki media 3 dimensi. Tujuan penelitian ini adalah untuk mendeskripsikan perancangan media video animasi pada mesin-mesin listrik yang menggunakan software blender. Oleh sebab itu, penelitian ini termasuk penelitian kualitatif deskriptif. Teknik pengumpulan data yang digunakan adalah perancangan media mesin-mesin listrik pada dua aspek yaitu (1) video animasi peralatan mesin-mesin listrik, dan (2) video animasi percobaan rangkaian mesin-mesin listrik. Data penelitian kemudian dianalisis secara induktif yang terdiri atas reduksi, penyajian data, dan verifikasi (penarikan kesimpulan). Hasil penelitian menunjukkan bahwa video animasi yang telah dihasilkan meliputi 7 komponen peralatan mesin-mesin listrik dan 7 video animasi percobaan rangkaian mesin-mesin listrik. Video animasi peralatan mesin-mesin listrik yang disajikan mampu menampilkan media 3D yang menyerupai aslinya. Pada video animasi rangkaian mampu menyajikan aliran arus untuk mengaktifkan komponen yang akan difungsikan. Melalui video animasi ini diharapkan mahasiswa dapat mengetahui, mengenal, dan memahami komponen dan prosedur kerja rangkaian untuk mesin-mesin listrik.
\end{abstract}

Kata Kunci: Media, Blender, Vidio Animasi, Mesin Listrik.

\section{DESIGN OF ANIMATION VIDEO MEDIA IN ELECTRIC MACHINE INSTALLATION AT BONTANG TECHNOLOGY HIGH SCHOOL}

\begin{abstract}
Learning activities during the COVID-19 pandemic are carried out online. The use of two-dimensional media is considered not enough to synergize with reality media, especially electric machines that have 3dimensional media. The purpose of this study was to describe the design of animated video media on electric machines using blender software. Therefore, this research is a descriptive qualitative research. The data collection technique used is the design of the media for electrical machines in two aspects, namely (1) animation videos of electrical machinery equipment, and (2) animated videos of experimental electrical machinery circuits. The research data was then analyzed inductively which consisted of reduction, data presentation, and verification (drawing conclusions). The results showed that the animated videos that had been produced included 7 components of electrical machinery equipment and 7 animated videos of experimental electrical machinery circuits. Animated videos of electrical machine tools that are presented are able to display $3 D$ media that resembles the original. In the animated video, the circuit is able to present the current flow to activate the components to be used. Through this animated video, students are expected to be able to know, recognize, and understand the components and working procedures of a circuit for electrical machines.
\end{abstract}

Keyword: Midea, Blender, Animated Video, Electric Engine. 


\section{PENDAHULUAN}

Dimasa pandemi covid-19, pembelajaran daring merupakan bentuk pembatasan sosial dan fisik di lingkungan pendidikan serta sesuai surat edaran Mendikbud No. 4 Tahun 2020 [1]. Guru dan siswa secara bersama sama mengoptimalkan berbagai platform online seperti zoom meeting [2], google meet [3], Ms. Teams [4], dan perpaduan antar berbagai platform untuk melaksanakan pembelajaran daring.

Platform online yang digunakan berfungsi sebagai media untuk melaksanakan kegiatan pembelajaran. Platform online memerlukan jaringan internet dalam penggunaanya. Ketidaktersediaan jaringan internet dapat menyebabkan kegiatan pembelajaran tidak terlaksana. Hal inilah yang menjadi satu perbedaan utama antara pembelajaran daring dan luring.

Pemanfaatan platform untuk melaksanakan pembelajaran online telah berlangsung lama semenjak terjadinya lonjakan kasus Covid-19 di Indonesia. Pembelajaran online telah diimplementasikan pada setiap jenjang pendidikan termasuk pendidikan tinggi. Inti dari pembelajaran baik online maupun onfline adalah terjadinya interaksi multi arah antara guru, siswa, dan sumber-sumber belajar.

Sumber belajar dapat berupa media pembelajaran. Media pembelajaran yang digunakan dapat berfungsi untuk memfasilitasi, mendukung pembelajaran [5], membangun interaksi, dan pengenalan dalam bentuk nyata/model. Oleh sebab itu, media pembelajaran dapat memberi kontribusi yang cukup dominan kepada siswa.

Pelibatan media pembelajaran perlu mempertimbangkan berbagai aspek. Aspek tersebut diantaranya adalah desain dan rancangan pembelajaran yang disusun, kebutuhan siswa, karakter siswa, dan tujuan yang akan dicapai. Keterampilan dan kemampuan guru dapat mempengaruhi kualitas media yang digunakan.

Penggunaan media dalam pembelajaran daring dapat memiliki perbedaan dengan media pada pertemuan yang dilakukan secara tatap muka. Media yang dapat digunakan dalam pembelajaran daring adalah video animasi untuk mengenalkan berbagai objek secara riil. Namun hal ini disadari oleh pengampu mata kuliah mesin-mesin listrik jarang dilakukan. Media yang digunakan selama ini cenderung media gambar (dua dimensi) selama pembelajaran daring yang dilaksanakan. Hasil wawancara terhadap mahasiswa diperoleh informasi bahwa mahasiswa tidak banyak mengenal bagian-bagiannya, tidak mengetahui cara mengoperasikannya, dan mengalami kesulitan dalam memahami mesin-mesin listrik.

Berdasarkan hasil wawancara, pelibatan media pembelajaran dalam bentuk dua dimensi akan ditransformasikan dengan menggunakan video animasi. Video animasi diyakini mampu menyajikan benda/objek yang dapat dilihat dengan sudut $360^{\circ}$. Dalam pembuatan video animasi ini, software yang dapat digunakan adalah software blender yang mampu menyajikan satu objek dalam bentuk 3D. Berbagai media yang menggunakan blender diantaranya adalah anaimasi 3D medan magnet [6], game edukasi [7], dan animasi interaktif 3D IPA [8]. Dengan menggunakan video animasi yang dibuat oleh pengampu mata kuliah diharapkan dapat mengantarkan mahasiswa mampu mengenal, mengetahui, dan mencapai pemahaman secara maksimal.

Hasil refleksi terhadap pembelajaran yang selama ini dilaksanakan dan pemanfaatan media dua, maka video animasi perlu dirancang dan digunakan dalam pembelajaran di kelas online. Oleh karena itu, tujuan yang akan dicapai pada penelitian adalah mendeskripsikan aktivitas perancangan media video animasi pada materi mesin-mesin listrik.

\section{METODE PENELITIAN}

Pendekatan penelitian yang digunakan peneliti adalah penelitian kualitatif. Hal ini berdasar pada penelitian yang tidak menguji kebenaran suatu hipotesis, namun lebih kepada mendeskripsikan aktivitas merancang video animasi pada materi mesin-mesin listrik. Peneliti pada penelitian ini sebagai instumen kunci yaitu terlibat secara langsung dari awal sampai menyusun laporan akhir. Dengan pendekatan penelitian dan peran peneliti maka penelitian ini termasuk penelitian kualitatif. Penelitian kualitatif merupakan penelitian dengan instrumen kuncinya adalah peneliti [9].

Data penelitian terdiri atas hasil perancangan yang meliputi dua aspek yaitu (1) perancangan video animasi peralatan mesin-mesin listrik, dan (2) perancangan video animasi percobaan rangkaian mesin-mesin listrik. Keseluruhan data hasil penelitian kemudian dianalisa secara induktif. Miles dan Huberman (1992) menyatakan bahwa pada penelitian kualitatif, analisa data meliputi reduksi data, penyajian data, dan penarikan kesimpulan (verifikasi) [10]. Sesuai dengan pendekatan dan jenis penelitian ini maka analisis data yang digunakan terdiri atas 3 (tiga) tahapan yaitu reduksi data, penyajian data, dan penarikan kesimpulan. Sedangkan untuk keabsahan data menggunakan triangulasi data sumber. 


\section{HASIL DAN PEMBAHASAN}

Software blender pada penelitian ini digunakan untuk merancang video animasi untuk mesin-mesin listrik. Terdapat 7 miniatur peralatan yang dapat diamati secara menyeluruh. Arah pergerakan peralatan tersebut berputar searah jarum jam dengan kecepatan standar yang membentuk sudut $360^{\circ}$. Miniatur peralatan dibuat menyerupai media aslinya agar mahasiswa mengenal, memahami bentuk peralatan dan mengetahui fungsi peralatan tersebut.

Miniatur peralatan yang dirancang dengan aplikasi blender dapat diamati pada setiap gambar $1-4$.

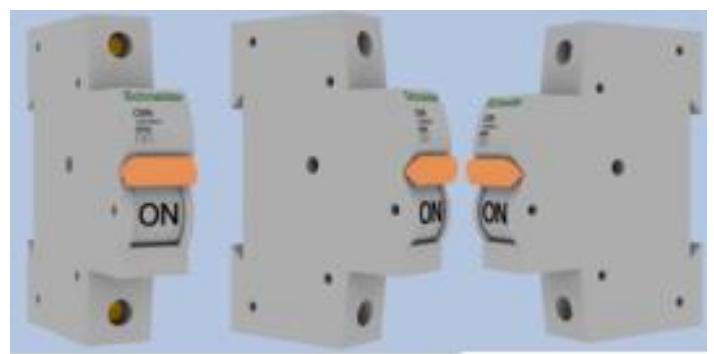

Gambar 1. Video animasi circuit breaker (MCB) 1 Phasa

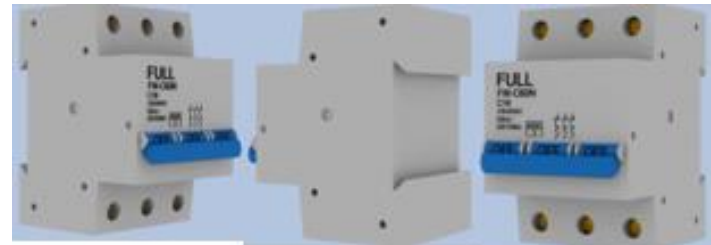

Gambar 2. Video animasi circuit breaker (MCB) 3 Phasa

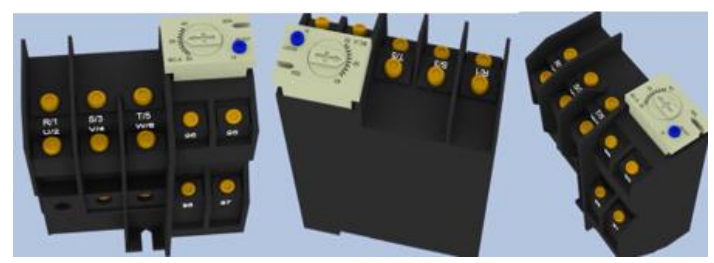

Gambar 3. Video animasi Thermal Overload Relay (TOR)

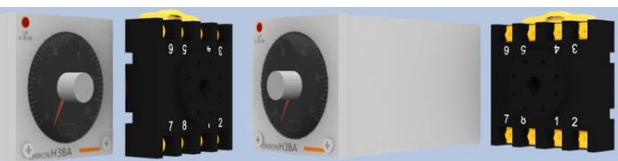

Gambar 4. Video animasi Time Delay Relay

(TDR)

Video animasi peralatan yang telah selesai dibuat, kemudian dilanjutkan dengan merancang video animasi berbagai percobaan. Terdapat video animasi percobaan rangkaian mesin-mesin listrik yang berhasil dibuat. Adapun hasil atas rancangan video animasi percobaan yang dimaksud disajikan pada gambar 5 - 7 .

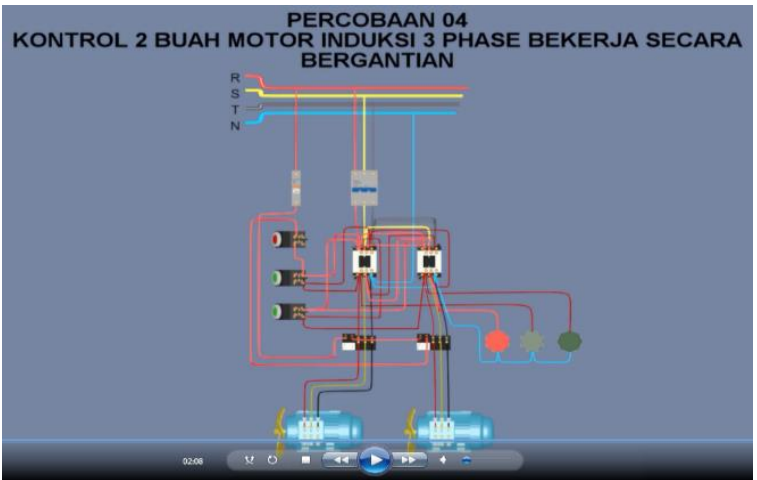

Gambar 5. Video animasi Kontrol 2 Buah Motor Induksi 3 Phase Bekerja secara bergantian

Animasi rangkaian kontrol 2 buah motor induksi 3 phase bekerja bergantian secara manual sebagaimana yang ditunjukkan pada gambar 5. Alur kerja rangkaian adalah dengan menghidupkan 2 motor induksi menggunakan saklar tombol Push Button sebagai kontrol utama agar motor listrik bekerja secara bergantian.

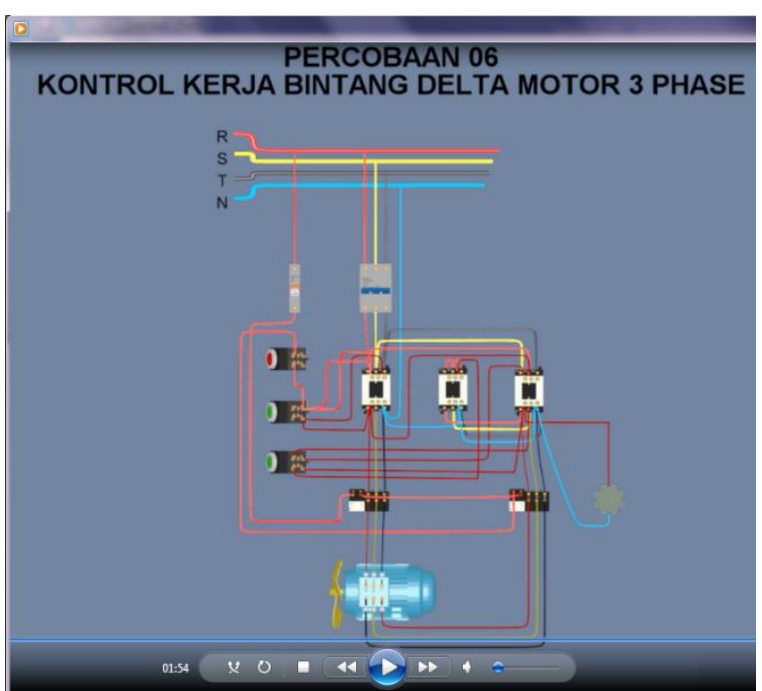

Gambar 6. Video animasi Percobaan Kontrol Kerja Bintang Delta Motor 3 Phase

Rangkaian kontrol kerja bintang delta motor 3 phase yang ditunjukkan pada gambar 6 menggunakan 3 buah kontaktor. Dimana kontaktor 1 bekerja sebagai penyalur daya utama ke motor untuk masuk terminal utama, sedangkan kontaktor 2 dan 3 sebagai penyambung hubungan Delta dan star. 


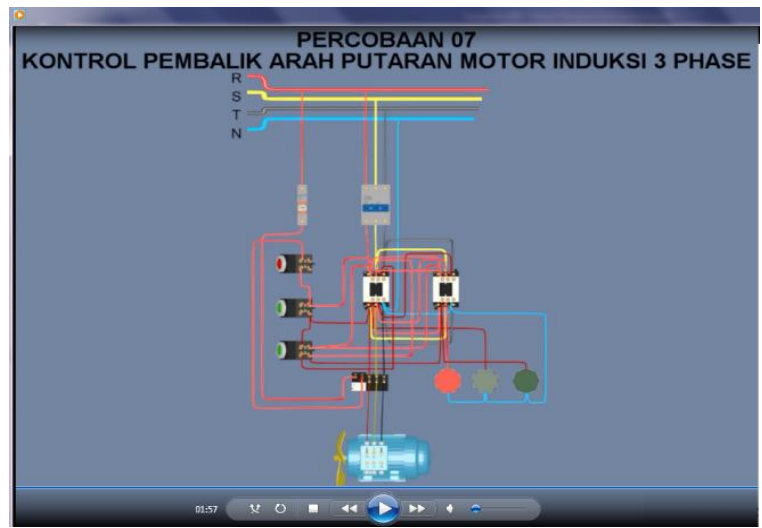

Gambar 7. Video animasi Percobaan Kontrol Pembalik Arah Putaran Motor 3 Phase

Pada gambar 7, animasi percobaan kontrol pembalik arah putaran motor 3 phase menunjukkan bahwa motor akan berputar ke kanan (forward), jika Kontaktor 1 (K1) bekerja. Saat kontaktor 1 bekerja, tegangan RST akan masuk ke motor secara berurutan. Dan video animasi diatas juga menjelaskan kalau motor akan berputar ke kiri (reverse), jika kontaktor 2 (K2) bekerja. Saat K2 bekerja maka polaritas tegangan RST yang masuk kemotor akan dibalik menjadi TSR. sehingga yang terjadi adalah motor akan berputar ke kiri. Untuk mengatur atau mengendalikan kedua kontaktor tersebut diperlukan rangkaian kontrol forward reverse.

Melalui video animasi yang digunakan sebagai media pembelajaran diharapkan dapat mengantarkan mahasiswa untuk mencapai pemahaman, mengetahui dan mengenal komponen peralatan mesin-mesin listrik secara realistik melalui contoh miniatur yang menyerupai aslinya dan sekaligus mampu menguasai prosedur kinerja atas suatu rangkaian.

\section{SIMPULAN}

Kesimpulan dari penelitian ini diantaranya Video animasi yang telah berhasil dirancang menggunakan software blender terdiri atas 7 komponen peralatan dan 7 percobaan rangkaian mesin-mesin listrik. Video animasi peralatan mesin mesin ditampilkan dalam bentuk 3 dimensi yang dapat dilihat dari segala arah. Sementara itu, video animasi pada rangakaian mesin mesin listrik menampilkan aliran arus listrik untuk memfungsikan komponen-komponen terkait.

\section{DAFTAR PUSTAKA}

[1] Mendikbud RI, Surat Edaran Mendikbud No. 4 Tahun 2020 Tentang Pelaksanaan Kebijakan Pendidikan Dalam Masa Darurat Penyebaran Coronavirus Disease (COvid-19).
2020.

[2] J. B. Kelana, M. A. Wulandari, and D. S. Wardani, "Penggunaan Aplikasi Zoom Meeting di Masa Pandemi Covid-19 Pada Pembelajaran Sains," Jurnal Elementary: Kajian Teori Dan Hasil Penelitian Pendidikan Sekolah Dasar, vol. 4, no. 1, pp. 18-22, 2021.

[3] K. Dewi, T. Pratisia, and A. K. Putra, "Implementasi pemanfaatan google classroom, google meet, dan instagram dalam proses pembelajaran online menuju abad 21," Jurnal Integrasi dan Harmoni Inovatif Ilmu-Ilmu Sosial, vol. 1, no. 5, pp. 533-541, 2021, doi: 10.17977/um063v1i5p533-541.

[4] A. S. Situmorang, "Microsoft Teams for Education Sebagai Media Pembelajaran," Microsoft Teams for Education Sebagai Media Pembelajaran Interaktif Meningkatkan Minat Belajar, vol. 02, no. 01, pp. 30-35, 2020.

[5] M. Miftah, "Pemanfaatan Media Pembelajaran Untuk Peningkatan Kualitas Belajar Siswa," KWANGSAN, vol. 1, no. 2, pp. 1-11, 2014.

[6] C. A. Caesaria, M. Jannah, and M. Nasir, "Pengembangan Video Pembelajaran Animasi 3D Berbasis Software Blender Pada Materi Medan Magnet," Southeast Asian Journal of Islamic Education, vol. 3, no. 1, pp. 41-57, 2020.

[7] N. Saurina, "Game Edukasi Sebagai Media Pembelajaran Untuk Kelas IV SDN Banjarsugihan II Menggunakan Blender 3D," Jurnal Sistem dan Informatika (JSI), vol. 2, no. 2, pp. 128-134, 2017.

[8] U. C. Affandi and H. Wibawanto, "Pengembangan Media Animasi Interaktif 3(Tiga) Dimensi sebagai Alat Bantu Ajar Mata Pelajaran IPA Kelas VII menggunakan Blender Game Engine," Jurnal Teknik Elektro, vol. 7, no. 2, pp. 62-70, 2015, doi: 10.15294/jte.v7i2.8586.

[9] M. Mulyadi, "Penelitian Kuantitatif dan Kualitatif Serta Pemikiran Dasar Menggabungkannya," 2011.

[10]U. Shidiq and M. Choiri, Metode Penelitian Kualitatif di Bidang Pendidikan, Edisi Pert. Ponorogo: CV. Nata Karya, 2019. 